\title{
Mitigation Technique of Voltage Flicker in Arc Furnace Using D-STATCOM
}

\author{
Anjali Gupta, Amit Tripathi
}

\begin{abstract}
Voltage flicker is the disturbance in voltage waveform due to the variation of load in the power system. Voltage flicker is the most important factor that effects the power quality of an electric arc furnace. voltage flicker causes the fluctuation in the light source that varies from time to time. Therefore, this paper deals with the study of Flexible AC Transmission Line (FACTS) based distribution static synchronous condenser (D-STATCOM) device that alleviates the voltage flicker from the arc furnace. The arc furnace is acting as current source and simulated in the MATLAB for obtaining the result.
\end{abstract}

Keywords- Voltage flicker, Flexible AC Transmission System, D-STATCOM, Electric arc furnace.

\section{INTRODUCTION}

The power system includes various electrical components such as transformers, bus bars, isolator, circuit breaker, relays, capacitor banks and reactors [1]. Therefore, it is very important to maintain the power quality of the power system to have reliable system [2],[3]. There are many factors that effects the power quality like voltage imbalance, voltage, flicker, harmonic distortion etc. [4]. Dynamic loads always generate harmonics in the power system and reduces the performance of electrical equipment. Electric arc furnace is such type of load which causes voltage fluctuation when connected to the grid in the electrical system thereby leading to the problem of voltage flicker [5],[6]. These power quality problems results in reduction of efficiency and performance of electrical equipment. Thus, there are many techniques that can be used in the power system to mitigate the problem of voltage flicker caused by the electric arc furnace [7]. In this paper the FACTS based device D-STATCOM is used to minimize the problem of voltage flicker caused by the arc furnace. Distribution Static Compensation (DSTATCOM) basically has a two function firstly, it can mitigate the problem of voltage flicker and secondly it also provides reactive power compensation [8].

Conventionally, static var compensator (SVC) were used to provide reactive power compensation as well as solving the problem of voltage flicker but due to some drawback this method is limited [9]. The static var compensator generates harmonics and the time response is very slow as compared to D-STATCOM device. The distribution static compensator is based on IGBT voltage source inverter (VSI) that is capable of actuating at very fast rate of response and eliminates the

Revised Version Manuscript Received on 10 September, 2019.

Anjali Gupta, Department of Electrical \& Electronics Engineering, Noida Institute of Engineering and Technology, Noida, U.P. India. (Email: researchnietip@gmail.com)

Amit Tripathi, Department of Electrical \& Electronics Engineering, Noida Institute of Engineering and Technology, Noida, U.P. India. (Email: researchnietip@gmail.com) generation of lower order harmonics and provide power factor correction to the electrical equipment. D-STATACOM also plays a great role in reducing the transient, voltage sag and voltage swell problem at the load end side of the power system. The algorithm used for modelling of DSTATCOM is very simple and takes less time to response.

\section{MODELING OF ELECTRIC ARC FURNACE}

The electric arc furnace along with the power system is shown in figure.1. In the below figure the power supply is given to an electric arc furnace load through a connected power system. This electric arc furnace generates a voltage flicker and to mitigate this flicker a D-STATCOM is inserted in between the electric arc furnace and the distribution line. This distribution static compensator unit provides the reactive power compensation thereby maintain the power quality of the electrical power system.

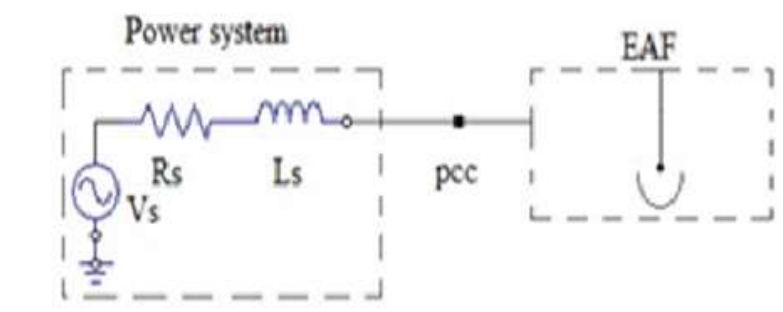

Fig, l. Power system model with Electric Arc Furnace Type Style and Fonts

Electric arc furnace is used by various industries in which a wide range of scrap can be melted to form a new shape or model. The arc furnace basically uses a pair of electrodes and supply of current. The modelling of electric arc furnace is performed in the MATLAB software which is shown by the figure below. 


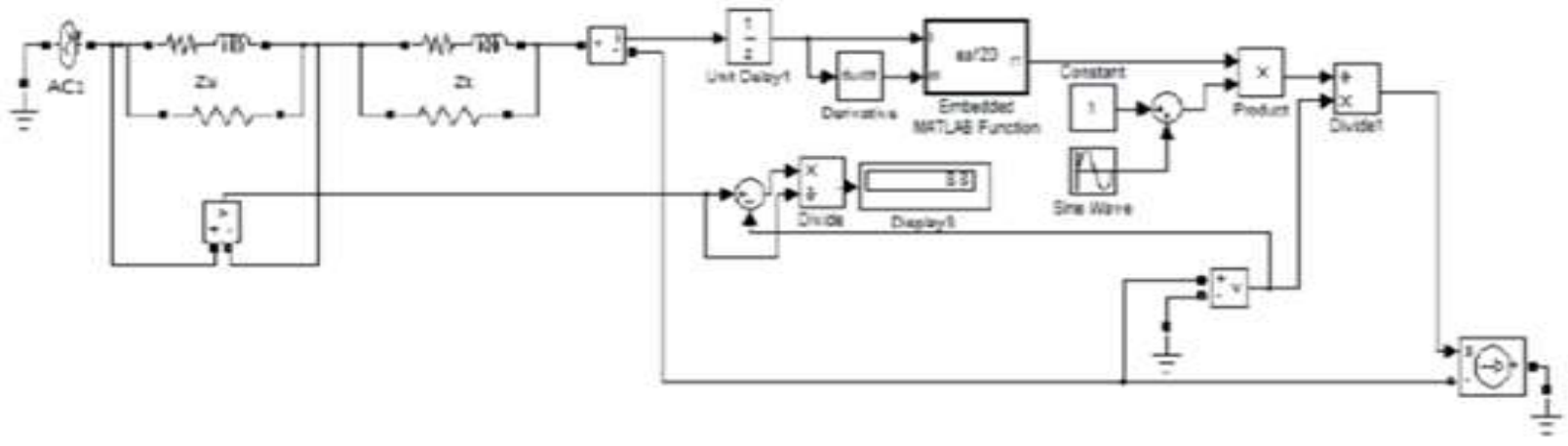

Fig. 2. Simulink model of Single phase EAF model

The modeling of electric arc furnace is tested and performed in MATLAB Simulink and is depends on many factors like voltage, current and length determined by moving in and out of electrodes. The acquisition of all the related parameters such as voltage data at PCC viewed using MATLAB.

\section{EAF Characteristics and Modeling}

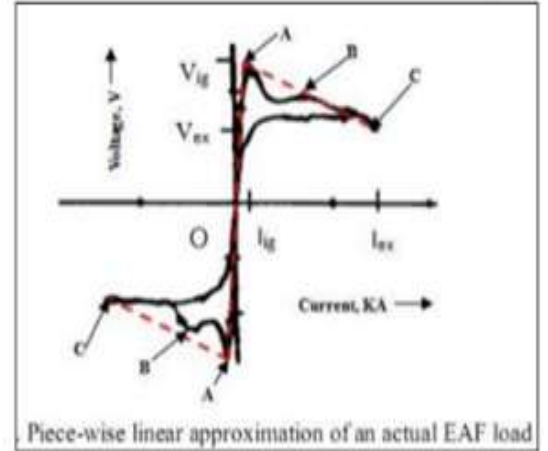

\begin{tabular}{|l|l|l|}
\hline arc & ignition & extinction \\
\hline voltage & $\mathrm{V}_{\text {ig }}$ & $\mathrm{V}_{\text {ex }}$ \\
\hline current & $\mathrm{I}_{\text {ig }}$ & $\mathrm{l}_{\text {ex }}$ \\
\hline
\end{tabular}

Fig.3. Electric arc furnace Characteristics

Fig. 3 shows resistance versus arc length characteristics of electric arc furnace. The characteristics obtained is a non linear approximated by piece-wise linear model. Slope of line $\mathrm{OA}$ is the resistance during pre-arcing $\mathrm{R} 1$, slope of line $\mathrm{AC}$ is the resistance during arcing $\mathrm{R} 2$, power of furnace is $\mathrm{P}$ in megawatt (MW).

\section{Modeling Equations:}

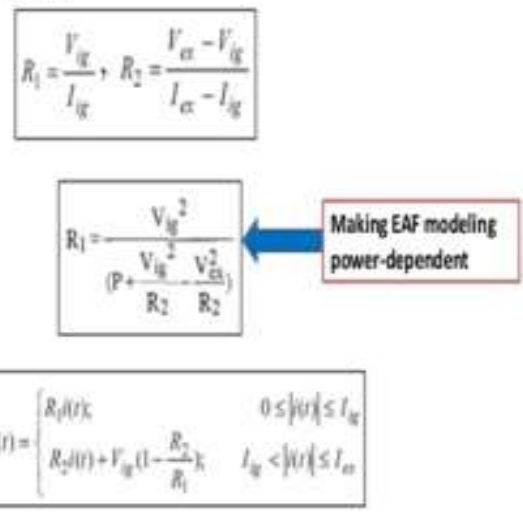

\section{RESULTS AND DISCUSSION}

The following result is obtained by performing an experiment in the MATLAB Simulink. The electric arc furnace is placed at the load side and the voltage flicker is generated in the simulation during the running of electric arc furnace. The resultant output voltage flicker and pure sinusoidal waveform is shown in fig.4. it is to be noted that this voltage waveform is produced before placing of distribution static compensator (D-STATCOM)

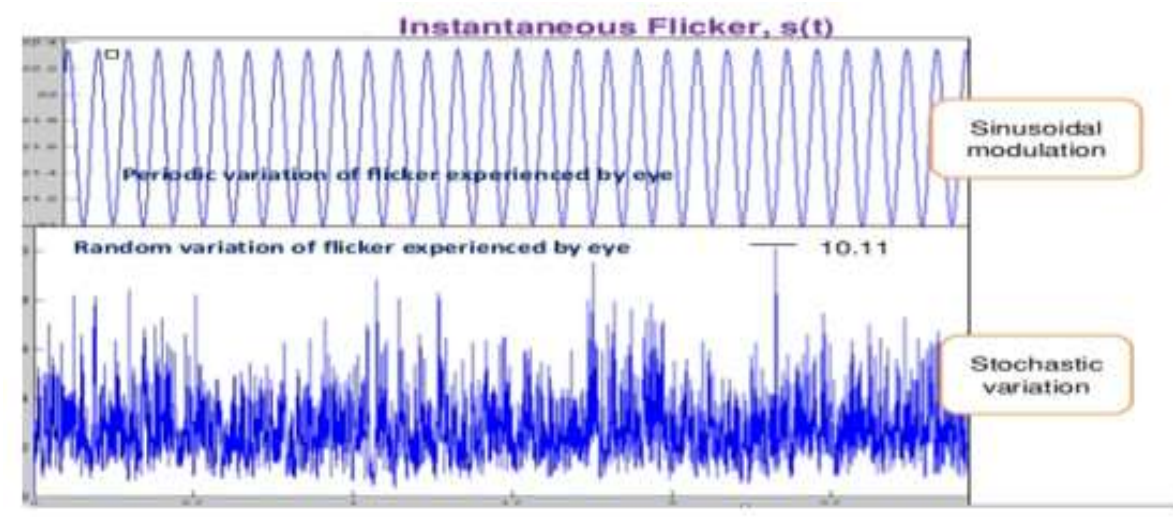

Fig.4 Flicker voltage before compensation 
Simulation parameters:

\begin{tabular}{|l|l|}
\hline $\mathrm{F}$ & $50 \mathrm{~Hz}$ \\
\hline $\mathrm{Zs}$ & $0.00052 \mathrm{~s}+\mathrm{j} 0.00468 \Omega$ \\
\hline $\mathrm{Zt}$ & $0.0003366+\mathrm{j} 0.00322 \Omega$ \\
\hline $\mathrm{Rs}$ & $0.05 \Omega$ \\
\hline $\mathrm{Vg}$ & $350.75 \mathrm{~V}$ \\
\hline $\mathrm{Imax}$ & $100 \mathrm{KA}$ \\
\hline $\mathrm{t1}$ & $0.01 \mathrm{sec}$ \\
\hline $\mathrm{t} 2$ & $0.01 \mathrm{sec}$ \\
\hline DC link voltage & $680 \mathrm{~V}$ \\
\hline DC link capacitor & $500000 \mu \mathrm{f}$ \\
\hline Coupling Inductance & $\mathrm{SmH}$ \\
\hline
\end{tabular}

From the above simulation result it is observed that the voltage flicker under sinusoidal modulation of arc resistance is significantly higher than the stochastic modulation. After generating voltage flicker in the simulation, the distribution static compensator which is inserted between the electric arc furnace load and distribution line eliminates or mitigate the generated voltage flicker thereby maintaining the power quality of the power system. Fig.5 represent uniform voltage waveform that is obtained after compensation and mitigation of voltage flicker

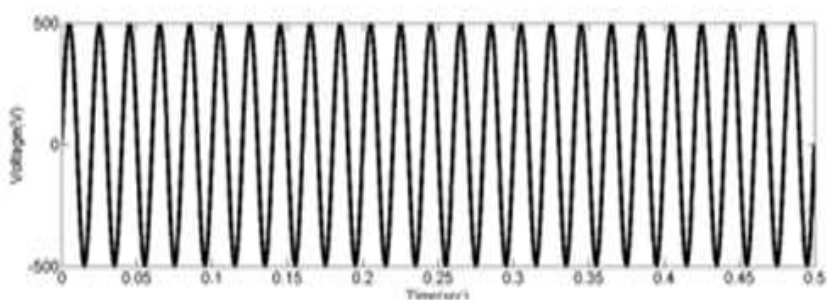

Fig.5. Source voltage after compensation

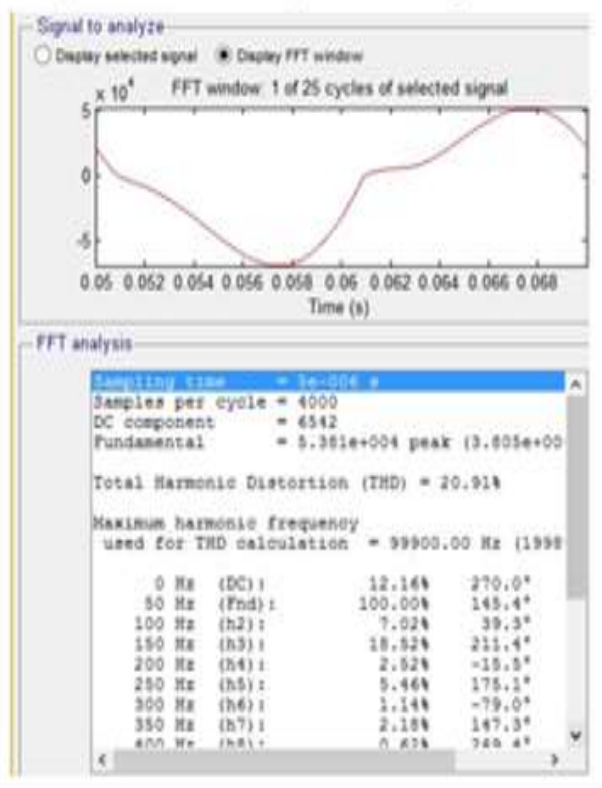

\section{CONCLUSION}

This paper focus on the development of mathematical system modeling strategy that can be applied to any power system for mitigating the voltage flicker generated during the operation of electric arc furnace. In this paper a detailed analysis, modeling and estimation of flicker in the power system is estimated. The simple and unique approach is used to determine the voltage flicker and minimizing the flicker. D-STATCOM is injected in between the EAF at the load side and the distribution line, this facts device provides reactive power to the distribution line and reduces the problem of voltage flicker thereby eliminating the lower order harmonics and transient in the power system.

\section{REFERENCES}

1. D. Kirschen and G. Strbac, Fundamentals of Power System Economics. 2004.

2. L. Benini, A. Bogliolo, and G. De Micheli, "A survey of design techniques for system-level dynamic power management," IEEE Transactions on Very Large Scale Integration (VLSI) Systems. 2000.

3. J. Arrillaga, "Power quality," in Systems, Controls, Embedded Systems, Energy, and Machines, 2017.

4. A. De Almeida, L. M. J. Delgado, P. Quality, P. Quality, P. Quality, and P. Quality, "Power Quality Problems and New Solutions Abstract : Key words," Power Qual. Probl. Solut., 1992.

5. J. Schlabbach, D. Blume, and T. Stephanblome, Voltage Quality in Electrical Power Systems. 2011.

6. A. T. Teklić, B. Filipović-Grčić, and I. Pavić, "Modelling of three-phase electric arc furnace for estimation of voltage flicker in power transmission network," Electr. Power Syst. Res., 2017.

7. X.-P. Zhang, C. Rehtanz, and B. Pal, "FACTS-Devices and Applications," 2012.

8. M. K. Mishra, A. Ghosh, and A. Joshi, "Operation of a DSTATCOM in voltage control mode," IEEE Trans. Power Deliv., 2003.

9. K. Al-Haddad, R. Saha, A. Chandra, and B. Singh, "Static synchronous compensators (STATCOM): a review," IET Power Electron., 2009. 